\title{
Teaching forest operations planning and operations research: An integrated approach to learning
}

\author{
by Evelyn W. Richards ${ }^{1}$ and E.W. (Ted) Robak ${ }^{1}$
}

\begin{abstract}
The Forest Engineering program at the University of New Brunswick is the only accredited forest engineering program in Canada, and one of the few in North America. One of the primary learning outcomes of the program includes the ability to design and analyze production systems, especially forest operations. This requires that Forest Engineering students be competent in use of operations research tools and techniques. Experience to date has confirmed that a progressive learning approach that requires students to apply operations research techniques to increasingly complex and realistic problems is essential for achieving these learning outcomes.
\end{abstract}

Key words: forest management, operations design, modelling, learning outcomes, forest engineers, curriculum, wood supply chain, progressive learning, education

\section{RÉSUMÉ}

Le programme de Génie forestier de l'Université du Nouveau-Brunswick est le seul programme de génie forestier agréé au Canada et l'un des rares à lêtre en Amérique du Nord. L'une des principales retombées de la formation dispensée par le programme est de pouvoir concevoir et analyser des systèmes de production, spécialement pour les opérations forestières. Cela nécessite de la part des étudiants en Génie forestier dêtre capables d'utiliser des outils et des techniques de recherche opérationnelle. L’expérience à ce jour a confirmé que l'approche progressive d’apprentissage qui oblige les étudiants à appliquer les techniques de recherche opérationnelle à des problèmes de plus en plus complexes et réalistes est essentielle pour atteindre ces niveaux d’apprentissage.

Mots clés : aménagement forestier, conception d’opérations, modélisation, niveaux d’apprentissage, ingénieurs forestiers, programme universitaire, chaîne d'approvisionnement en matière ligneuse, apprentissage progressif, formation

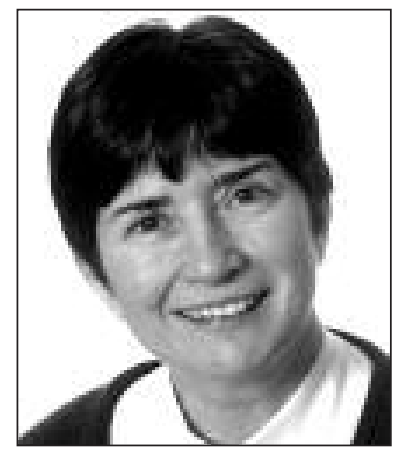

Evelyn W. Richards

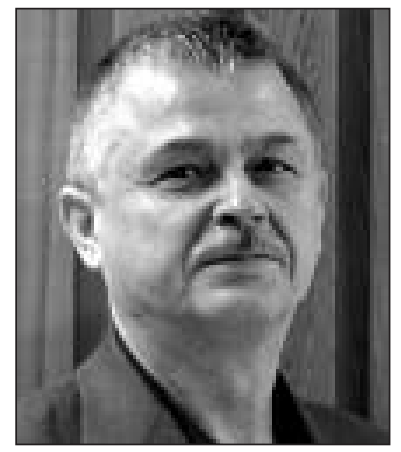

E.W. (Ted) Robak

\section{Introduction}

The Forest Engineering (FE) programme in the Faculty of Forestry and Environmental Management at the University of New Brunswick (UNB) is the only such programme accredited in Canada, and one of the few in North America. The ultimate technical outcomes of the programme are that students will be able to design and analyze structures and production systems in natural resource settings. Design criteria for these structures and systems include both economic and environmental sustainability. Production systems include those that operate mostly in the natural environment, such as

harvesting and transporting forest products, as well as those that occur in more controlled environments such as in woodprocessing plants.

\section{Wood Supply Chain}

Supply chain management is key to efficiency and sustainability in any industry. Operations planning is the initial step in management of the wood supply chain and, given the costs and risks involved, a critical one. It is also the tertiary implementation phase of an integrated hierarchical forest management process that must be properly undertaken if sustainable forest management is to be achieved.

In comparison with other industries, managing the wood supply chain presents some unique challenges. Timber products are both size- and species-dependent. Upon felling, an individual tree may be converted into several products. Natural stands in Canadian forests have a wide diversity of species, sizes, and qualities of trees, and hence an individual harvest block may produce as many as 10 to 20 timber products. These products must be produced and distributed to facilities in the required amount and quality, and at the time they are demanded. Timber products carry stringent requirements for freshness, limiting the potential to use inventories to balance the supply chain. Furthermore, forestry production systems must work in a natural environment that is less controllable and more uncertain than is the case of most

${ }_{1}^{1}$ Professors and P.Eng's, Faculty of Forestry and Environmental Management, University of New Brunswick, P.O. Box 44555, Fredericton, New Brunswick E3B 6C2. E-mails respectively: ewr@unb.ca, robak@unb.ca 
industrial situations. In addition to economic concerns, forest operations must be carefully undertaken to mitigate negative short- and long-term impacts on soils, water, and wildlife. Ultimately, planning must take into account multiple stakeholders and time horizons so as to ensure a sustainable flow of the many benefits and values that can be obtained from forested environments.

In this complex decision environment, a disaggregated problem-solving approach is unlikely to result in optimal or even acceptable plans. Local decisions by a production operator that are optimal when only the immediate environment and business conditions are considered may be globally ruinous. Thus, it is not surprising that operations research methods such as optimization and simulation are essential tools for supporting forest operation decision-making.

In this paper, we describe our methodology for teaching about decision-making in forest operations planning and operations research principles and techniques in an integrated manner.

\section{Operations Research}

The Institute for Operations Research and Management Sciences has dubbed Operations Research (OR) the "Science of Better." It is the discipline of applying advanced analytical methods to help make better decisions, and includes mathematical modelling, simulation, and an informed approach to gathering and using data. OR allows decision-makers to explore complex situations fully and to improve their decision-making.

We expect our graduates to be competent OR practitioners, informed OR users, and managers of system uncertainty. A competent practitioner uses OR to solve common, limitedsize problems using a basic set of techniques. An informed user communicates and deals effectively with consultants and others who offer OR-based solutions. A manager of system uncertainty strives to quantify stochastic system elements and includes these elements in system analysis to assess robustness of solutions.

The educational strategy we use to help students acquire these abilities has three essential elements:

- Students learn the methodology and science of a restricted set of techniques, their OR "toolset."

- Students apply these tools first to problems of limited size and complexity to gain practice in formulating models, producing solutions, and analyzing results.

- Students then are tasked to solve successively larger, more complex, and less defined problems.

The problems that we use to teach OR are based on problems of wood supply chain management. The OR learning begins in a class that is devoted mostly to learning techniques and practising on small problems. It is then fully integrated into courses on forest operations planning. In this way, learning about OR is complemented by learning relevant to the programme's other technical outcomes.

\section{Planning/Designing Forest Production - Distribution Systems}

As part of the FE curriculum and course design process, we have defined course outcomes and the abilities that a graduate forest engineer must possess in order to competently undertake production system planning. According to these definitions, our graduates must be able to:
- Characterize the problem in terms of context, objectives, constraints, resources and evaluation criteria;

- Identify alternative solution strategies and choose the most appropriate solution strategy;

- Identify and design alternative solutions;

- Choose and justify a recommended solution;

- Finalize the design of the chosen solution in a manner that facilitates organization and implementation.

Assuming that long-term forest management decisions have been made at the strategic and tactical levels of the hierarchical forest management planning process, operational planning focuses on the design of industrial production processes at two distinct levels: the Multi-Year Operating Plan (MYOP) and the Annual Operating Plan (AOP). While meeting the constraints of strategic and tactical plans, and taking into account environmental and social regulations and policies, forest engineers must design efficient and effective MYOPs that answer the following questions:

- What harvesting systems should be used in which blocks in which seasons of which years, given that different systems have different costs, production capabilities, silvicultural implications and road requirements?

- What products should be produced in which blocks and transported by which transportation systems to which mills or buyers in which seasons of which year?

- Where should tertiary, secondary, and sometimes primary roads be built in which years?

- What equipment should be purchased or contracted in which years?

- What silvicultural activities should be undertaken by which methods and systems in which years?

Following the MYOP planning phase, an annual operations planning process that considers the first year's activities of the MYOP is undertaken. The AOP is a detailed schedule of forest operations activities at a finer time resolution (days, weeks, months) that is used to assess implementation concerns, verifying that all road construction, harvesting, wood transport and silvicultural operations can be undertaken in the time and manner specified in the MYOP. Annual planning addresses supply chain issues such as inventory levels and product freshness. It is the basis of the annual budget and cash flow projections.

For most industrial forest operations in Canada, the forest operation-planning problem is large and complex, and it does not take much deviation from optimality to result in huge cost increases or profit reductions. This problem lends itself to use of optimization and other operations research techniques that help produce plans that are more efficient, effective and robust. From a pedagogical point of view, identifying appropriate operations research techniques and designing and using optimization and simulation models improves students' abilities to analyze and design forest operations, enhances their skills in sensitivity and risk analysis, and also introduces these techniques to a new generation of operations managers in an industry that needs to become more efficient.

\section{The Courses}

The three primary courses in the production systems stream are one operations research course and two operations planning courses. Our students begin the stream with an introductory course in Operations Research where they learn about OR methods and apply them to limited-size problems. 
The OR learning is then continued in Forest Operations I where students build heuristics, linear programming, and mixed integer programming models to solve a "real-sized" forest operations planning problem. Finally, in Forest Operations II, emphasis is moved from building models to using them to undertake extensive sensitivity analyses and to identify and take into account relevant externalities such as those related to environmental or social concerns that are not required by regulations or policies.

\section{Operations Research I}

In Operations Research I, students are introduced to solving resource-constrained optimization problems by heuristic methods, mathematical programming, and simulation. They learn about linear, integer, and mixed integer programming, network models (spanning tree and shortest path), and both deterministic and stochastic simulation. Students are also introduced to supply chain concepts such as raw materials sourcing, transportation, and inventory.

These methods are presented in a variety of application contexts. Students then solve a simplified wood supply problem using all of the OR techniques that are being learned. The problem is explored through an initial solution developed using linear programming, an expanded situation that builds integer solutions to incorporate fixed costs and discrete decisions, and a simulation model that is used to assess variability in the system and its impact on productivity, throughput, safety stock levels and cost of inventory. Simulation is also used to analyze a queuing situation and recommend equipment capacity decisions that meet performance criteria related to the stochastic elements of the system.

\section{Forest Operations Planning I}

The first course in forest operations planning integrates knowledge learned in previous courses about production systems and OR. It introduces students to problems of designing operations plans that have both spatial and temporal constraints, and that have multiple goals, which compete against each other. The outcomes of this course are to be able to:

- Design forest level operations that occur over multiple planning periods, and at more than one level (e.g., MYOP - AOP), and with economic, social and environmental objectives.

- Use operational research methods like heuristics, simulation, and mathematical programming to create and assess plans.

- Use knowledge of stand-level operations, production machines, and inventory issues to make and assess production and transportation choices in forest operations plans.

- Analyze plans for comprehensiveness, feasibility, optimality, external acceptance, and robustness using scenario analysis and sensitivity analysis.

The course is structured around a moderately complex operations planning problem for a "client" that demands an optimized solution. Creating this solution requires students to gather and analyze data, and to create a series of models that they use to analyze various scenarios.
It should be noted that, before building and using any optimization model, students generate a "quick and dirty" solution to the problem using heuristics. This exercise is important because students learn about the problem scope and complexity by solving it with the heuristic, and they have a basis to compare the benefits of optimization tools in achieving better solutions and in creating a systematic methodology for incorporating constraints, doing scenario analysis, and sensitivity analysis.

\section{Forest Operations Planning II}

In the final operations planning course, emphasis is less on building models and more on using existing models to undertake extensive sensitivity analyses and plan improvement. Given an initial plan involving several hundred harvest blocks, over a dozen mills and markets, several harvesting and transportation options and well over a hundred roads, students must quickly identify and analyze areas of potential improvement, explore alternatives and then choose and justify an ultimate solution that describes the operating decisions for each season and year. They must then demonstrate that this MYOP can be used to prepare a realistic AOP. The presented problem is large and complex enough that application of heuristics alone would be unlikely to lead to feasible solutions, much less to an optimal one. They are required to justify their new plan, the methods they used to develop it and to identify major areas of risk and uncertainty.

\section{Conclusion}

Despite the recent economic downturn in the Canadian forest industry, there will continue to be forest operations in the future. However, these operations must be more efficient and plans must be more robust and flexible if the cost of delivered wood is to be reduced so that Canadian companies can be competitive while maintaining environmental and social values associated with our public forests. Such companies need to have managers who are better able to undertake the analysis and planning that result in operational efficiency and robustness. Use of optimization tools and techniques helps to develop the knowledge and skills needed by such managers.

Our experience to date has confirmed that a progressive learning approach that requires students to apply operations research techniques to increasingly complex and realistic problems has a significant impact on their learning outcomes related to production planning in an industrial forestry setting. Our students spend much more time formulating and solving problems than on learning theory, and they concentrate on a limited set of techniques. The payback is that students can actually solve problems, recognize the value and limitations of results, and know how to use OR tools to undertake real-world analyses. When students are required to choose and apply appropriate operations research techniques to solve analysis and planning problems, they gain a much deeper and broader understanding of the operational design process at the same time that they learn about the capabilities and limitations of OR techniques, models and analytical tools. 